\title{
Le Moyen Âge vu d'ailleurs III. La Edad Media desde otros horizontes III.
}

Antropología histórica y arqueología : perspectivas y estudios en curso. Madrid, Casa de Velázquez, 15-18 de junio de 2005

\section{Pascual Martínez Sopena}

\section{(2) OpenEdition} Journals

Édition électronique

URL : https://journals.openedition.org/cem/586

DOI : $10.4000 /$ cem.586

ISSN : 1954-3093

Éditeur

Centre d'études médiévales Saint-Germain d'Auxerre

Édition imprimée

Date de publication : 15 août 2006

ISSN : 1623-5770

Référence électronique

Pascual Martínez Sopena, "Le Moyen Âge vu d'ailleurs III. La Edad Media desde otros horizontes III. », Bulletin du centre d'études médiévales d'Auxerre | BUCEMA [En ligne], 10 | 2006, mis en ligne le 13 octobre 2006, consulté le 22 septembre 2022. URL : http://journals.openedition.org/cem/586 ; DOI : https:// doi.org/10.4000/cem.586

Ce document a été généré automatiquement le 22 septembre 2022.

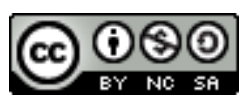

Creative Commons - Attribution - Pas d'Utilisation Commerciale - Partage dans les Mêmes Conditions 4.0 International - CC BY-NC-SA 4.0

https://creativecommons.org/licenses/by-nc-sa/4.0/ 


\section{Le Moyen Âge vu d'ailleurs III. La Edad Media desde otros horizontes} III.

Antropología histórica y arqueología : perspectivas y estudios en curso. Madrid, Casa de Velázquez, 15-18 de junio de 2005

\section{Pascual Martínez Sopena}

1 En el mes de junio, la ciudad de Madrid ofrece buen tiempo y calles animadas. La capital de España es un excelente sitio para estimular la discusión y, sin duda, este hecho ha gravitado sobre el éxito del coloquio, el tercero de una serie que tiene vocación de continuidad.

2 Las observaciones iniciales que deseo hacer tienen mucho de notas de ambiente. La primera, que quienes han intervenido en estos días han evocado a varios maestros distintos y próximos: como Reyna Pastor -que inauguró virtualmente el coloquio en la voz de su discípula Ana Rodríguez-, Pierre Guichard, José Mattoso o Pierre Bonnassie, desaparecido recientemente. Todos ellos han estado presentes en unas jornadas que, concebidas como una reflexión sobre las relaciones entre la historia medieval y la antropología, era razonable que resaltasen la deuda de la historiografía hispánica con algunos de los autores que han incorporado las preocupaciones de las ciencias sociales a su oficio

3 En segundo lugar, es visible que en el entramado del coloquio estaban previstas varias sesiones con un perfil muy bien definido. Me refiero a aquéllas que se han dedicado a la arqueología, o a la música, las fiestas y los juegos. Así se ha cumplido, como más adelante se procurará destacar. Pero estos cuatro intensos días han permitido apreciar en toda su amplitud otra circunstancia: la variedad de nexos entre las comunicaciones. Ahora, cuando se cierra el coloquio, este hecho permite hacer una lectura diferente del programa desarrollado. A modo de síntesis, habrá que señalar que su principal virtud ha sido contribuir a la viveza de las discusiones.

4 Varios ejemplos me vienen a la mente. A escala de sesiones distintas, pienso en las presentaciones sobre "la Edad Media en América" y "la Reconquista", que tienen una 
peculiar derivación en las fiestas que Antonio RUBIAL y José Rivair MACEDO nos han descrito, entre México y el sur del Brasil ${ }^{1}$. Del mismo modo, el trabajo de Alain RAUWEL y los de Eduardo AUBERT y Étienne ANHEIM ofrecen un visible paralelismo en lo relativo a la liturgia y la música ${ }^{2}$. O las relaciones entre el arte y la Reforma de la Iglesia según nos las han presentado Daniel RUSSO y Estelle HUP-DAHAN, son un perfecto preludio de la Archéologie du bâti que preocupa a Christian SAPIN $^{3}$. Es verdad que la ausencia de Dominique Iogna-Prat aplaza una discusión sobre la Reforma de la Iglesia y el "momento figurativo", tanto en sus perspectivas generales como en sus particularidades regionales; de cualquier modo, dejo constancia de ello, en espera de otro momento para re-suscitar la cuestión.

Pero también dentro de una misma sección cabe establecer nexos nuevos o imprevistos. Como indicó Patrick HENRIET reflexionando sobre los estudios de Hector FRANCISCO y Ariel GUIANCE, que hablaban de dos sitios tan aparentemente lejanos, Babilonia y España, donde se revelan dos vertientes de un mismo problema, el de las relaciones de las comunidades cristianas con el poder ${ }^{4}$.

6 En el resto de las observaciones deseo destacar ciertos temas que me parecen particularmente susceptibles de discusión.

7 Uno es la herencia medieval en América, que Hilario FRANCO JUNIOR ha comentado con pasión, enfatizando su carácter arcaizante ${ }^{5}$. Pero ¿de qué Edad Media estamos hablando? Como parece razonable, la cultura -en su sentido más amplio-, que emigra al otro lado del Atlántico y lo coloniza ha fraguado en la Baja Edad Media hispánica. Ésta época conoció en la Península -particularmente en Castilla y Portugal-, dos fenómenos de signo muy distinto que llegaron a ser compatibles. Por una parte, el crecimiento de los poderes señoriales (sobre todo, de los señoríos laicos a costa del realengo). Por otra, el aggiornamento de un factor de cohesión social: dentro de una gran variedad de situaciones, las comunidades locales poseían una capacidad relativamente grande para organizar su territorio. Dicho de otra manera, el control del espacio por los vecinos del lugar (un hecho que venía de antiguo), se adaptó a las nuevas circunstancias de apropiación privada de las tierras del rey e incluso se afianzó mediante acuerdos perpetuos. Además, las monarquías mantuvieron una superioridad jurisdiccional poco discutible. No es que todo esto fuera trasplantado mecánicamente, pero es posible que tales realidades -con su complejo imaginario-, influyeran de modo decisivo en la sociedad del nuevo mundo, y que lo hicieran de forma duradera. En todo caso, las metrópolis y las colonias tuvieron ritmos diversos de evolución, así como una evolución interna llena de matices. Tal vez el mundo ultramarino mantuvo un carácter más tradicional, que puede ser considerado arcaizante con el paso del tiempo. La pregunta que dejo sobre la mesa se refiere a si el triunfo del liberalismo -esto es, la emancipación-, desgarró a la sociedad de las jóvenes repúblicas tan profundamente como ocurrió en la Península.

8 Ahora bien, la gran cuestión de la "Reconquista" propone un contrapunto sobre estos mismos problemas. Este proceso representa una realidad distinta, menos amable y, desde luego, un cúmulo de experiencias transferibles. Pero antes hay que detenerse en un asunto semántico, pues el uso del citado término ha protagonizado momentos de intensa discusión en estos días; resumiéndola, puede decirse que el coloquio ha escenificado los puntos de vista divergentes de la historiografía española sobre el significado del proceso y el grado de desacuerdo sobre su convencional denominación, como expusieron Carlos de ayala y Martín Ríos ${ }^{6}$. Lo que parece indudable es que 
"Reconquista" o expansión de los reinos cristianos hacia el sur han generado por lo común situaciones de sometimiento y segregación; además, un ambiente de rechazo del "los otros" con frecuencia ha provocado la ruina cultural o el éxodo de las poblaciones vencidas o diferentes, así como brotes de violencia. Las reflexiones de Christophe CAILLEAUX lo ponen claramente de relieve ${ }^{7}$. ¿Acaso América no conoció nuevas versiones de tales modos de actuar, íntimamente arraigados por generaciones en quienes fueron sus conquistadores? ¿Hasta que punto pudieron ser controlados o fueron tenidos como modelo, estimulados? Todas las respuestas posibles incluyen, sin ningún género de dudas, una referencia a la Edad Media peninsular; conviene advertir que la coexistencia de cristianos con judíos y musulmanes (en ciertas regiones, sumaban éstos últimos o su progenie, formalmente bautizada, la mayoría de la población), no tuvo el tono armonioso que se supone o se desea ver.

9 La arqueología medieval, según se adelantaba, ha tenido un papel singular en la última jornada de un coloquio que pretendía destacar su aportación y compararla a escala de Francia, España y Portugal. Desde luego, ha resultado patente la dificultad para establecer un umbral común porque el desarrollo y los rumbos de la disciplina son muy diversos. Hay que tener en cuenta que en Francia, uno de los grandes problemas del momento es revisar los criterios de datación, y otro la "arqueología de lo construido" de que ya se ha hablado. Mientras, en Portugal destaca el interés por la arqueología islámica y por los castillos; estos últimos tienen a su favor una corriente de sensibilidad colectiva que los ha convertido en un objeto de culto nacional. Por lo que hace a España, el panorama resulta más complicado por la diversidad de administraciones y por el predominio de una arqueología de gestión; las comunidades autónomas -que poseen las competencias en esta materia-, no mantienen las mismas políticas, y con frecuencia se carece de programas estratégicos adecuados ${ }^{8}$.

10 En tanto en arqueología es básico el planteamiento territorial y, más aún, local, al analizar los juegos y las fiestas esa perspectiva cuenta mucho menos. Lo relevante es la tensión entre lenguajes cultos y lenguajes populares, como ha puesto de relieve Jean Claude Schmitt, sobre áreas dilatadas, y, desarrollando esa problemática, la conexión, traslación o interpenetración de unos y otros. Por otro lado, el examen de las fiestas propone espectáculos donde el ritual y el orden es escrupuloso, y donde la ostenctación se convierte en el modo de pregonar el prestigio y la hegemonía social, todo ello sin olvidar que se trata de "ritos de consenso", como destacaba Juan Carlos Martín CEA. Todo esto se plasmó en el análisi de la influencia de ciertos grupos solidamente estructurados, en particular los frailes mendicantes, o del papel ambivalente de otros animadores sociales, como los juglares, unos y otros estudiados y asociados por Martine CLOUZOT ${ }^{9}$. También condujo a ejercicios de etnografía histórica completamente necesarios, que trataban de los tiempos, espacios y ambientes de las actividades lúdicofestivas, como para la ocasión hicieron Flavio de CAMPOS y Juan Carlos Martín CEA, ya citado ${ }^{10}$; si bien es conocida la tradición de las fiestas de toros, que ambos comunicantes destacaron en Castilla y Portugal, la panoplia es mucho más amplia, y sin duda sería apta para lanzar una encuesta a escala continental.

11 Como puede verse, el encuentro de Madrid ha puesto de relieve un extenso abanico de problemas. Queda por agradecer a la Casa de Velásquez, lugar idóneo para este tipo de reuniones, su hospitalidad: a su director, el profesor Gérard CHASTAGNERET, y al responsable de programas, profesor Pierre MORET. Uno y otro animaron las sesiones, además de cumplir impecablemente con su papel anfitrión. Y, en último lugar pero no 
en el menos importante, creo expresar la opinión de todos si resalto que Eliana MAGNANI, la coordinadora del encuentro, ha hecho una labor excelente. Como nos tiene acostumbrados. Muchas gracias.

Rappel des communications

• “Autour de Reyna Pastor”, Ana Rodríguez (CSIC)

• "Imagenes y vidas de santos de la Edad Media en Nueva España. La violencia como mensaje", Antonio Rubial Garcia (Univ. Nac. Autónoma de Mexico)

- "Raízes medievais do Brasil", Hilário Franco Jr. (Univ. de São Paulo)

- "Mouros e Cristãos: a ritualização da conquista no Velho e no Novo Mundo", José Rivair Macedo (Univ. Federal de Rio Grande do Sul)

- "La " Reconquête", une aspiration Péninsulaire ? Étude comparative entre deux traditions historiographiques”, Martín Ríos Saloma (Univ. Complutense de Madrid)

- "Reconquista, cruzada y órdenes militares”, Carlos de Ayala (Univ. Autónoma de Madrid)

• "Cristianización y tradiciones cultuales en Vasconia", Roldán Jimeno Aranguren (Univ. Pública de Navarra)

- "Les juifs et les musulmans dans les sources normatives du xive siècle à Barcelone et à Tortosa", Christophe Cailleaux (Univ. de Bourgogne)

- "Hagiografía, exégesis y la construcción de una identidad eclesiástica en el oriente cristiano, siglos VII al IX dC", Héctor Francisco (Univ. de Buenos Aires, Univ. Nac. de General Sarmiento)

- "Milagros y prodigios en la hagiografía castellana altomedieval”, Ariel Guiance (Conicet Argentine)

- "Espaces symboliques et espaces concrets de l'action liturgique au Moyen Âge latin", Alain Rauwel (Univ. de Bourgogne)

- "Uma litania para o rei? Som e sentido na sagração real a partir do Ordo ad consecrandum et coronandum regem (c.1250)”, Eduardo Aubert (Univ. São Paulo)

- "Musique et culture dans la cour pontificale d'Avignon", Étienne Anheim (École Française de Rome)

- "La figure du jongleur", Martine Clouzot (Univ. de Bourgogne)

- "Os jogos e a temática lúdica em Portugal no final da Idade Média", Flávio de Campos (Univ. de São Paulo)

- "Fiestas y juegos en Castilla a fines de la Edad Media", Juan Carlos Martín Cea (Univ. Valladolid)

- “La réforme de l'Église et le moment figuratif dans l'art religieux - xie-xiie siècles", Daniel Russo (Univ. de Bourgogne)

- “Une architecture monastique et la réforme de l'Église : l'exemple des établissements de chanoines de Saint-Augustin dans le diocèse de Sens et d'Auxerre", Estelle Hup-Dahan (Univ. de Bourgogne)

- "De l'archéologie à l'histoire, nouvelles approches sur le bâti des monuments religieux en France, 1985-2005”, Christian Sapin (CNRS Auxerre/Dijon)

• “Arqueologia medieval em Portugal : duas décadas de investigação”, Isabel Cristina Fernandes Ferreira (archéologue municipale de Palmela, Portugal)

- "Balance de la arqueología medieval cristiana en España", Julio Escalona (Instituto de Historia, CSIC)

- "L'archéologie islamique en Espagne", Patrice Cressier (CNRS - Lyon)

- Ont également participé : Patrick Henriet (Univ. Bordeaux 3), Marta Madero (Univ. Nac. de General Sarmiento, Argentine), Eliana Magnani (CNRS Dijon/Auxerre), Pascual Martínez 
Sopena (Univ. de Valladolid, Espagne), Joseph Morsel (Univ. Paris I), Jean-Claude Schmitt (EHESS Paris).

\section{NOTES}

1. A. RUBiAl garcíA, “Imágenes y vidas de santos de la Edad Media en Nueva España”. Así, Nueva España -el actual México-, asumió la condición guerrera que la Reconquista había dado a San Isidoro o a Santiago matamoros (en América, mataindios como en Santiago Tlatelolco), o la devoción a la Inmaculada concepción (bien arraigada en el siglo xv español). En el coloquio que siguió a la conferencia, D. Russo subrayó la estrecha relación de las imágenes americanas con la iconografía que alentaron los dominicos y franciscanos desde la segunda mitad del siglo XIV. J. RIVAIR MACEDO, "Mouros e Cristãos: a ritualização da conquista no Velho e no Novo Mundo", donde mostró la importancia de temas propios de la Reconquista, incluida la figura de Roldán, en el folklore del sur del Brasil, y su significado en el fortalecimiento de las identidades locales colectivas; los problemas de la utilizació del fondo folklórico fueron comentados sagazmente por Joseph Morsel.

2. Los tres comunicantes se explayaron sobre el sentido social de un arte litúrgico que está penetrado de hermetismo, observando que su examen desde puntos de vista antropológicos y arqueológicos es un tema en expansión. En términos más específicos, A. RAUWEL, "Espaces symboliques et espaces concrets de l'action liturgique au Moyen Âge latin", examinó ciertos problemas de lexicografía, del espacio litúrgico y de la construcción de una "identidad sacerdotal" que culmina e el siglo XV; E. AUBERT, "Uma litania para o rei? Som e sentido na sagração real a partir do ordo ad consecrandum et coronandum regem (c. 1250), reflexionó sobre cómo lo sonoro no sólo expresa relaciones entre Dios, el clero y el rey, sino que también las crea, y además prestó su propia voz para ilustrar su exposición; E. ANHEIM, "Musique et culture dans la cour pontificale d'Avignon", valoró la profesionalización del músico y el acento elitista de la ars nova como parábola del poder.

3. D. RUSSO, "La réforme de l'Église et le moment figuratif dans l'art religieux $\left(\mathrm{XI}^{\mathrm{e}}-\mathrm{XII}^{\mathrm{e}}\right.$ siècles)", defendió una cierta "renovación paleocristiana" del arte del siglo XI, al mismo tiempo que postulaba la ausencia de control del arte figurativo por los reformadores; E. HUP-DAHAN, “Une architecture monastique et la réforme de l'Église: l'exemple ds établissemnets de chanoines de Saint-Augustin dans les diocéses de Sens et d'Auxerre", en una línea paralela al anterior, destacó la primacía de peculiaridades regionales; Ch. SAPIN, "De l'archéologie à l'historie, nouvelles approches sur le bâti des monuments religieux en France, 1985-2005”, aportó un extenso análisis de casos que recorrían toda Francia, buena muestra de la fecundidad del trabajo reciente.

4. H. FRANCISCO, "Hagiografía, exégesis y la costrucción de una identidad eclesiástica en el oriente cristiano, siglos VII a IX d. C.", donde desgranó la experiencia de los monofisitas, herederos de la tradición rigorista de la Iglesia oriental opuesta al nestorianismo, que formaron una iglesia clandestina hasta bien entrada la época 
musulmana y construyeron su identidad con ayuda de la hagiografía de sus obispos; A. GUIANCE, "Milagros y prodigios en la hagiografía castellana altomedieval", tras examinar la gracia especial de los obispos antiguos, significada en su báculo, destacó el movimiento de los "mártires voluntarios", aquellos mozárabes que defendieron las esencias de la tradición visigótica inmolándose y escribiendo, así como su concepción de la santidad basada en la virtud individual y ajena a los portentos.

5. H. FRANCO Jr., "Raízes medievais do Brasil". El autor hace un ensayo de psicología colectiva y de crítica historiográfica para un país donde se han negado tradicionalmente las continuidades a favor del mito del nuevo mundo; en su beneficio utiliza el concepto de "larga Edad Media" propuesto por Le Goff, los arcaísmos de la lengua portuguesa usada en Brasil (que tienen sus paralelos en la América española y el Canadá francófono), para concluir que la historia de Brasil tiene mucho de Moyen Âge vécu ailleurs.

6. M. Ríos SAlOMA, "La 'Reconquête', une aspiration péninsulaire? Étude comparative entre deux traditions historiographiques", puso en duda que la lucha contra el Islam fuera un anhelo común, al señalar que la Cataluña del siglo X, intensamente visigótica e integrada dentro de la monarquía franca, no tenía las necesidades a que condujo en Asturias la voluntad de legitimación y reconstrucción interesada del pasado; C. DE AYALA, "Reconquista, cruzada y órdenes militares", que tomó como referencia los siglos posteriores, destacó la superposición entre la idea tradicional de "reconquista" y la de "cruzada", que se impone a fines del siglo XI y termina equiparándose a las expediciones a Tierra Santa, que permanece bajo control de los reyes, y que halla su principal instrumento en las nuevas órdenes militares hispánicas.

7. Ch. CAILLEAUX, "Les juifs et les musulmans dans les sources normatives du XIV siècle à Barcelone et Tortosa". En ambas ciudades había una amplia población judía, y en la segunda también existió una considable comunidad musulmana; hombres propios del rey y beneficiados por leyes protectoras, las normas de segregación respecto a los cristianos aparecen en el siglo xIII, pero no afectan por igual a las dos comunidades, pues entre los judíos hay minorías notablemente enriquecidas e influyentes (algo peligroso en los momentos de violencia), lo que no sucede con los moros, mucho menos estructurados. P. CRESSIER, "L'archéologie islamique en Espagne".

8. Como ya se ha indica a propósito del estudio de Ch. Sapin, los arqueólogos ofrecieron sólidos balances de una tarea que, en conjunto, presenta estimulantes resultados. La comunicación de I. C. FERNANDES FERREIRA, "Arqueología medieval en Portugal: duas décadas de investigação”, comparó la dispersión de esfuerzos que reinó hasta mediados de los años 1970 con las innovaciones posteriores; ciertos debates, como el del mozarabismo de la alta Edad Media, siguen abiertos, pero la arqueología medieval se enseña en la universidad. Por su parte, J. ESCALONA, "Balance de la arqueología medieval cristiana en España", se detuvo particularmente en algunas regiones; en el caso del País Vasco, por ejemplo, el desarrollo arqueológico se ha producido como reacción a las carencias de la documentación escrita, mientras en el territorio de Madrid se saluda la existencia de actividades programadas. P. CRESSIER, "L'archéologie islamique en Espagne", tras aludir al dilatado conflicto de intereses mantenido por los historiadores y los filólogos en torno a al-Andalus, señaló hasta que punto la obra de P. Guichard ha innovado las orientaciones apoyándose en la antropología y la arqueología. Después ha venido una realidad enriquecida y paradójica: hay una jungla de publicaciones, no existen departamentos específicos de arqueología medieval islámica y los arqueólogos se ven forzados a una falsa autonomía. 
9. M. сLоuzot, "La figure du jongleur", donde los juglares son presentados a modo de "intermediarios culturales del siglo xIII" y "seres ambivalente", entre lo demoníaco y lo sagrado (en concordancia esto último con la pastoral de los mendicantes); sus perfiles resultan todavía más complejos si se piensa en la figura del clérigo giróvago, ilustrado y ajeno a disciplina.

10. F. DE CAMPOS, "Os jogos e a temática lúdica em Portugal no final da Idade Média" ha destacado que las reglamentaciones sobre juegos se articulan con los procesos políticos y fundamenta la tipología lúdica sobre dos hechos: el patrocinio de las autoridades sobre fiestas, ceremonias y celebraciones de plazo fijo, y la escasa sumisión de los juegos (de azar o de tablero), a un control disciplinario; en relación con lo cual, I. C. FERREIRA apuntó las aportaciones de la cultura material para enriquecer la problemática. J. C. MARTín CEA, "Fiestas y juegos en Castilla a fines de la Edad Media", presentó sus ensayos de tipología basados en los ritos de paso (incluidos los lances caballerescos), las manifestaciones colectivas, y los juegos en el interior y en el exterior. 